\title{
Análise físico-química da superfície de titânio após tratamento químico de descontaminação com clorexidina: estudo in vitro
}

\author{
Physical and chemical analysis of the titanium surface after chemical \\ treatment of decontamination with chlorexidine: in vitro study \\ Eduardo Henrique de Souza OLIVEIRAa (D), Marcelo Yudi SAKAMOTOa (i), Giovana CARNEIROa (D), \\ Viviane Maria RANKEL ${ }^{a}$ (D) , Geisla Mary Silva SOARES ${ }^{a}{ }^{(1)}$, Humberto Osvaldo SCHWARTZ-FILHO** (1) \\ aUFPR - Universidade Federal do Paraná, Departamento de Estomatologia, Curitiba, PR, Brasil
}

\begin{abstract}
Como citar: Oliveira EHS, Sakamoto MY, Carneiro G, Rankel VM, Soares GMS, Schwartz-Filho HO. Análise físico-química da superfície de titânio após tratamento químico de descontaminação com clorexidina: estudo in vitro. Rev Odontol UNESP. 2020;49:e20200075. https://doi.org/10.1590/1807-2577.07520
\end{abstract}

\begin{abstract}
Resumo
Introdução: Tratamentos têm sido propostos para a peri-implantite com o objetivo de descontaminar a superfície dos implantes, removendo microrganismos que podem estar associados à doença. Objetivo: 0 objetivo deste estudo foi avaliar a ação in vitro de diferentes métodos de aplicação de digluconato de clorexidina (CLX) na descontaminação de discos de titânio (Ti) com microtopografia e seu efeito físicoquímico sobre a superfície. Material e método: Vinte discos de Ti foram expostos a inóculo de Escherichia coli por 24 horas. Foram distribuídos em quatro grupos de descontaminação (n=5): 1 - um minuto de exposição à solução de CLX 0,12\%; 2 - dois minutos de exposição à solução de CLX 0,12\%; 3 - esfregaço durante um minuto com gel de CLX 1\%; 4 - esfregaço durante um minuto com gel de CLX 2\%. 0 produto de cada disco foi diluído e plaqueado individualmente. Após 24 horas, realizou-se contagem das unidades de colônias formadas (UFC). Resultado: 0 grupo com o menor número de crescimento de UFC foi o grupo 4 $(0,20 \pm 0,37)$, com apenas UFC em uma das amostras. Seguido do grupo $2(0,40 \pm 0,73)$, grupo 1 $(18,60 \pm 33,96)$. 0 grupo 3 apresentou as maiores quantidades de UFC $(36,07 \pm 41,39)$. Em todas as amostras, foi possível observar uma diminuição estatisticamente significante da concentração superficial de Ti, assim como um aumento de Oxigênio. Conclusão: Pode-se concluir que o uso de CLX gel a 2\% em superfícies de Ti com microtopografia contaminadas com E. coli propicia a eliminação das UFC e que sua aplicação resulta em diminuição do percentual de Ti e aumento do teor de 0.
\end{abstract}

Descritores: Clorexidina; peri-implantite; implante dentário.

\begin{abstract}
Introduction: Treatments have been proposed for peri-implantitis aiming to decontaminate the implants` surface removing microorganisms associated with the disease. Objective: The objective of this study was to evaluate the in vitro action of application of chlorhexidine digluconate (CLX) in the decontamination of titanium (Ti) discs with microtopography and its chemical-physical effect on the surface. Material and method: Twenty Ti discs were exposed to the Escherichia coli inoculum for 24 hours. Distributed equally in 4 decontamination groups $(\mathrm{n}=5)$ : 1 - one minute of exposure to the $0.12 \%$ CLX solution; 2 - two minutes of exposure to the $0.12 \% \mathrm{CLX}$ solution; 3 - smear for 1 minute with $1 \% \mathrm{CLX}$ gel; and 4 - smearing for 1 minute with $2 \%$ CLX gel. The product was diluted and plated individually. After 24 hours, colony units formed (CFU) were counted. Result: The group with the lowest number of CFU growth was group $4(0.20 \pm 0.37)$ with only one CFU in one of the samples. Followed by group $2(0.40 \pm 0.73)$, group 1 (18.60 \pm 33.96$)$, and group 3 , which presented the highest amounts of CFU (36.07 \pm 41.39 ). In all samples it was possible to observe a statistically significant decrease in the surface concentration of $\mathrm{Ti}$, as well as an increase in Oxygen. Conclusion: It can be concluded that the use of $2 \%$ CLX gel on Ti surfaces with microtopography contaminated with E.coli allows the elimination of CFU, and that its application results in a decrease in the percentage of Ti and an increase in the content of 0 .
\end{abstract}

Descriptors: Chlorhexidine; peri-implantitis; dental implants. 


\section{INTRODUÇÃO}

Apesar do grande sucesso alcançado com implantes osseointegrados na prática clínica, o número de complicações neste tipo de tratamento ainda é significativo. Em uma revisão sistemática e metanálise publicada por Derks et al. ${ }^{1}$, demonstrou-se a prevalência de complicações com média de $22 \%$ nas Américas e na Europa. Em um estudo clínico, com acompanhamento de 10 anos, observou-se uma taxa de $21,17 \%$ de falhas em implantes ${ }^{2}$. Complicações podem ocorrer precocemente durante as fases trans ou pós-operatória, ou tardiamente, durante a fase protética. As principais complicações relacionadas ao período tardio são na maioria as de condições inflamatórias, sendo as principais a mucosite peri-implantar e a peri-implantite ${ }^{3}$.

A peri-implantite ocorre pelo acúmulo de biofilme ao redor do implante e apresenta sangramento e/ou supuração após delicada sondagem, aumento da profundidade de sondagem em relação a exames prévios e presença de perda óssea ${ }^{4}$. Considerando-se a semelhança dos aspectos clínicos e microbiológicos entre as doenças peri-implantares e as periodontais ${ }^{5}$, várias terapias empregadas em periodontia foram também propostas para as doenças peri-implantares com o objetivo de reduzir o número de espécies patogênicas e melhorar o perfil clínico dos sítios peri-implantares.

São propostos tratamentos cirúrgicos e não cirúrgicos para essa doença, entre os quais estão o debridamento mecânico, os antibióticos locais e sistêmicos, e as terapias a laser. Porém, a completa remoção do biofilme, que seria o objetivo ideal das terapias propostas, é extremamente difícil de ocorrer. Além disso, é observado que os tratamentos aplicados podem causar também alguma modificação sobre a superfície do implante, seja esta química ou física, como, por exemplo, abrasão, corrosão e alterações da composição da superfícié.

Apesar de estudos abordarem diversas técnicas e opções de tratamento para essa complicação, ainda não existe o padrão ouro quando abordamos terapias para peri-implantite7. O objetivo do uso de agentes químicos é a total descontaminação da superfície de Ti, no entanto essa situação de completa descontaminação não é observada na literatura. Observe-se que, além de eliminar a presença bacteriana e suas toxinas, o agente químico ideal deve ser passível de sua completa remoção, devolvendo assim à superfície suas características de biocompatibilidade fundamentais para a re-osseointegração ${ }^{8}$.

Um importante agente antimicrobiano usado para controle de biofilme em dentes é a clorexidina (CLX) ${ }^{9}$, também usada para pacientes com doenças peri-implantares ${ }^{10}$. Diferentes concentrações foram usadas para avaliar o seu efeito na descontaminação de superfícies de implantes ${ }^{11,12}$. Esse agente pode ser usado em diferentes dosagens e frequências, no entanto não há consenso sobre sua eficácia na redução do acúmulo de biofilme nas superfícies dos implantes de Ti.

O objetivo deste estudo foi avaliar a ação in vitro de diferentes concentrações e métodos de aplicação da CLX na descontaminação de discos de titânio (Ti) com microtopografia, e seu efeito físico-químico sobre esta superfície.

\section{MATERIAL E MÉTODO}

\section{Obtenção dos Discos de Titânio}

Vinte amostras de Ti utilizadas neste trabalho foram confeccionadas e cedidas pela empresa NEODENT ${ }^{\circledR}$ (Curitiba, Paraná, Brasil), no tamanho $10 \mathrm{~mm} \times 2 \mathrm{~mm}$. Estas amostras, compostas por Ti comercialmente puro (grau 4), foram usinadas no formato de discos. A microtopografia foi 
obtida por um processo de jateamento com partículas de óxido de alumínio, seguido de um procedimento de condicionamento ácido (propriedade comercial).

A caracterização da topografia das amostras foi feita no nível micrométrico usando interferômetro ótico e microscopia de força atômica para avaliação. 0 cálculo paramétrico foi realizado após a remoção de erros de forma e ondulações por um filtro Gaussiano $(50 \mathrm{~mm} \times$ $50 \mathrm{~mm})$. Os seguintes parâmetros tridimensionais foram selecionados: Sa $(\mu \mathrm{m})$, referente à rugosidade média; $\operatorname{Sds}\left(\mu \mathrm{m}^{-2}\right)$, referente à densidade de picos, e $\operatorname{Sdr}(\%)$, referente ao aumento da área da superfície. Microscopia eletrônica de varredura foi utilizada para a avaliação da morfologia das superfícies. E, para avaliação da química de superfície, foi utilizada a espectroscopia por energia dispersiva de raios $\mathrm{X}^{13}$.

\section{Contaminação Bacteriana das Superfícies dos Discos de Titânio}

Para a contaminação dos discos de Ti, foi utilizada a espécie bacteriana Escherichia coli (E. coli) ATCC 25922, pertencente à família Enterobacteriaceae ${ }^{14}$. Um inóculo de E. coli foi preparado a partir de colônias cultivadas por 24 horas em LB ágar (Sigma-Aldrich, MO, USA), sendo dispersos 2,1 mL por poço em uma placa de 24 poços. Os discos de titânio foram fixados, com o auxílio de anteparo plástico esterilizado, na tampa da placa. Fechando a placa com a tampa contendo os discos, estes ficaram submersos no inóculo e então foram incubados em condição de aerobiose a $37^{\circ} \mathrm{C}$ por 24 horas 15,16 .

\section{Descontaminação das Amostras}

Após exposição à E. coli, os discos de titânio foram divididos em cinco grupos para receber diferentes métodos de descontaminação: Grupo 1 - Um minuto de exposição à solução de CLX 0,12\%; Grupo 2 - Dois minutos de exposição à solução de CLX 0,12\%; Grupo 3 - Esfregaço durante 60 segundos com gel de CLX 1\% com algodão estéril em cada face; Grupo 4 - Esfregaço durante 60 segundos com gel de CLX $2 \%$ com algodão estéril em cada face.

Todos os processos de descontaminação foram feitos pelo mesmo operador. Antes e após os procedimentos de descontaminação, os discos foram mergulhados em solução tampão fosfatosalino (PBS) 1x (LGC Biotecnologia - SP/BR) 1\% para remoção de células bacterianas que não estivessem aderidas. Em seguida, os discos foram colocados em uma nova placa contendo $2 \mathrm{~mL}$ PBS 1\% por poço e sonicados por 20 segundos. 0 produto de cada disco foi diluído em série e $20 \mu \mathrm{L}$ da solução nas concentrações de $10^{-1}$ e $10^{-3}$ foram plaqueados individualmente em placas de LB ágar. As placas foram incubadas em aerobiose a $37^{\circ} \mathrm{C}$ e, após 24 horas, foi feita contagem das colônias cultivadas.

\section{Microscopia Eletrônica de Varredura e Energia Dispersiva de Raios X}

Para uma análise da morfologia, foi usado um microscópio Tescan Vega3 LMU (Tescan, Brno, República Tcheca). A constituição elementar das amostras foi avaliada por energia dispersiva de raios X (EDX, Oxford Instruments, Abingdon). Essas análises foram realizadas no Centro de Microscopia Eletrônica (CME) da Universidade Federal do Paraná (UFPR). Das 20 amostras, foram selecionados quatro discos para os ensaios de microscopia eletrônica de varredura (MEV) e energia dispersiva de raios X (EDS), sendo um representante de cada tipo de tratamento de descontaminação, de forma aleatória ${ }^{17}$. As micrografias avaliadas foram obtidas tanto por elétrons retroespalhados (BSE) quanto por elétrons secundários (SE). A magnificação das imagens foi de $5 \mathrm{kx}$. Todas as imagens foram adquiridas utilizando um potencial de $10 \mathrm{kV}$. A análise das imagens se deu de forma visual, por um avaliador experiente, na procura de possíveis 
padrões de formação de oxidações, acidificação e também abrasão da superfície. Os espectros de EDS foram obtidos utilizando uma energia de 0 até 5,5 keV. Foram adquiridos espectros EDS de três regiões aleatórias pontuais sobre a superfície das amostras. As amostras foram submetidas ao processo de descontaminação e, na sequência, foram levadas para análise de MEV. Não foi realizado nenhum tipo de preparação de amostra para realização das imagens de microscopia e as obtenções de espectros de EDS.

\section{Análise Estatística}

A análise estatística foi aplicada aos dados numéricos obtidos através da análise visual com auxílio do Programa GraphPad Prism (versão Prism 8 for Mac OS X, San Diego), adotando-se em todos os testes o nível de significância de $5 \%(\alpha=0,05)$. Em primeiro momento, foi aplicado teste para observar normalidade dos dados. Na sequência, foi aplicado o teste de Kruskal-Wallis com pós-teste de comparação múltipla de Dunn.

\section{RESULTADO}

\section{Amostras e Caracterização das Superfícies Pré-contaminação}

A caracterização dos discos utilizados no estudo foi realizada previamente e se encontra publicada na literatura ${ }^{13}$. Resumidamente, características da topografia das superfícies foram qualitativamente avaliadas por microscopia eletrônica de varredura. A química de superfície foi estudada através de espectroscopia de dispersão de energia. Análises topográficas realizadas utilizando interferômetro óptico e microscopia de força atômica confirmaram a presença de microtopografia. 0 resultado mostrou que a sua modificação não resultou em alterações na composição química do material, predominantemente de titânio.

\section{Aplicação dos Antimicrobianos Locais}

Os dados da contagem foram transformados em logaritmo e submetidos à comparação. Como resultado, observou-se que a superfície dos discos foi susceptível à colonização bacteriana por E. coli. Comparando os grupos de descontaminação, foi observado que o grupo com o menor número de crescimento de UFC foi o grupo $4(0,20 \pm 0,37)$, com apenas UFC em uma das amostras. Seguido do grupo $2(0,40 \pm 0,73)$ e do grupo $1(18,60 \pm 33,96)$. Verificou-se que o grupo 3 apresentou as maiores quantidades de UFC $(36,07 \pm 41,39)$ (Figura 1).

\section{MEV}

Os resultados da MEV confirmaram a microtopografia de superfície apresentada pelos discos de titânio utilizados neste estudo e não mostraram diferenças em relação à morfologia das superfícies após a descontaminação (formação de oxidações, acidificação e abrasão da superfície). Conforme observado nas micrografias (Figura 2), não é possível identificar diferenças entre a morfologia das superfícies de titânio que passaram por tratamento de descontaminação e a morfologia da superfície controle, tanto na imagem de elétrons secundários (SE) quanto na imagem de elétrons retroespalhados (BSE). 


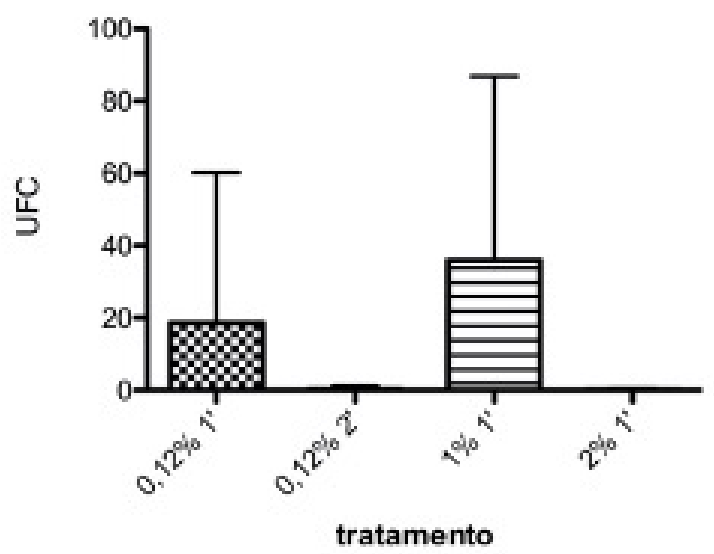

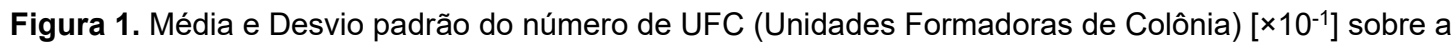
superfície de Ti. 0,12\% 1'- Solução de Clorexidina (CLX) a 0,12\% por um minuto; 0,12\% 2'- Solução de CLX a $0,12 \%$ por dois minutos; $1 \%$ 1'- Gel de CLX a $1 \%$ por um minuto; $2 \%$ 1'- Gel de CLX a $2 \%$ por um minuto.
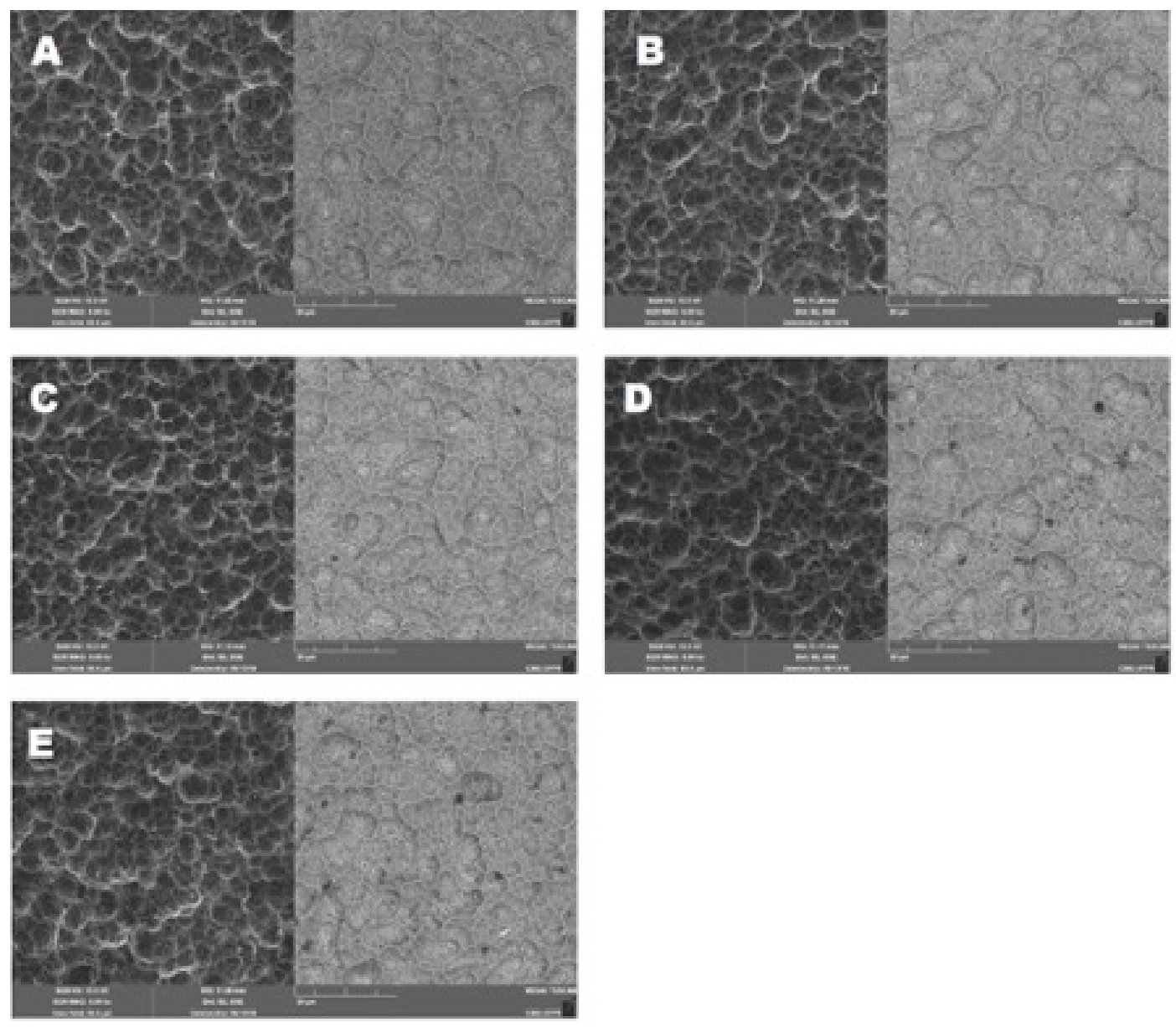

Figura 2 - Micrografias das amostras utilizando elétrons retroespalhados (BSE), esquerda, e elétrons secundários (SE), direita. (A) Controle; (B) Solução de Clorexidina (CLX) a 0,12\% por um minuto; (C) Solução de CLX a 0,12\% por dois minutos; (D) Gel de CLX a 1\%; (E) Gel de CLX a 2\%.

Nas imagens de elétrons retroespalhados (Figura 2), nota-se, para todas as amostras, uma grande superfície de densidade homogênea proveniente do retroespalhamento do feixe devido à superfície de titânio. Algumas regiões mais claras desta imagem refletem a ocorrência das 
irregularidades da microtopografia. Nas imagens de elétrons secundários (Figura 2), é possível observar uma similaridade da morfologia entre as amostras.

\section{EDS}

A química de superfície foi estudada através de espectroscopia de dispersão de energia. Em todas as amostras, foi possível observar uma diminuição estatisticamente significante da concentração superficial de titânio (Ti), assim como um aumento de oxigênio (0) na superfície, quando comparados à amostra controle, porém sem diferença entre os grupos de descontaminação avaliados. Os elementos Carbono, Flúor, Silício, Cálcio e Alumínio, apesar de presentes em pequena porcentagem, não tiveram variações consideráveis entre os grupos. A Figura 3 apresenta o espectro de um ponto de cada amostra. Os valores de média e desvio padrão de cada grupo são mostrados na Tabela 1.
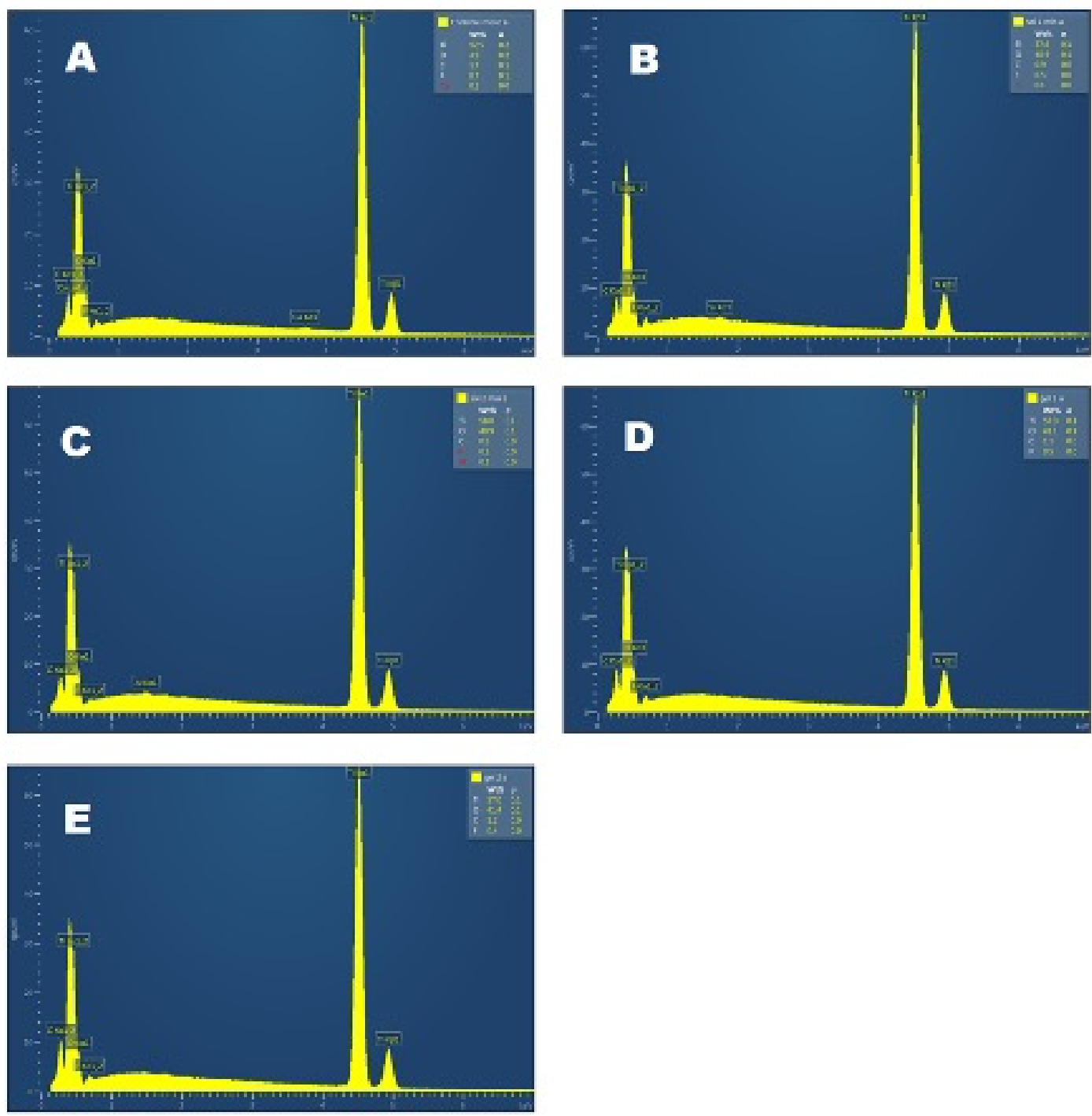

Figura 3. Espectros de EDS de um ponto das amostras, (A) Controle; (B) Solução de Clorexidina (CLX) a 0,12\% por um minuto; (C) Solução de CLX a 0,12\% por dois minutos; (D) Gel de CLX a 1\%; (E) Gel de CLX a $2 \%$. 
Tabela 1. Microanálise dos discos, apresentando as médias e desvios padrões (DP) dos elementos químicos detectados pelo EDS, com valores médios dados em porcentagem

\begin{tabular}{|c|c|c|c|c|c|c|c|c|c|c|}
\hline & \multicolumn{2}{|c|}{ Controle } & \multicolumn{2}{|c|}{ Solução - 1 min } & \multicolumn{2}{|c|}{ Solução - 2 min } & \multicolumn{2}{|c|}{ Gel 1\% } & \multicolumn{2}{|c|}{ Gel 2\% } \\
\hline & Média & DP & Média & DP & Média & DP & Média & DP & Média & DP \\
\hline $\mathrm{Ti}$ & 93,0 & 0,4 & 57,4 & 0,3 & 57,7 & 0,4 & 56,7 & 0,5 & 56,8 & 0,3 \\
\hline 0 & 4,6 & 0,2 & 41,1 & 0,2 & 41,0 & 0,1 & 41,4 & 0,3 & 41,5 & 0,2 \\
\hline $\mathrm{C}$ & 1,5 & 0,2 & 1,0 & 0,1 & 0,9 & 0,1 & 1,3 & 0,2 & 1,3 & 0,2 \\
\hline $\mathrm{F}$ & 0,8 & 0,0 & 0,5 & 0,0 & 0,3 & 0,1 & 0,5 & 0,0 & 0,4 & 0,0 \\
\hline $\mathrm{Si}$ & 0,0 & 0,0 & 0,1 & 0,0 & 0,0 & 0,0 & 0,0 & 0,0 & 0,0 & 0,0 \\
\hline $\mathrm{Ca}$ & 0,1 & 0,1 & 0,0 & 0,0 & 0,0 & 0,0 & 0,0 & 0,0 & 0,0 & 0,0 \\
\hline $\mathrm{Al}$ & 0,0 & 0,0 & 0,0 & 0,0 & 0,07 & 0,0 & 0,0 & 0,0 & 0,0 & 0,0 \\
\hline
\end{tabular}

Ti - Titânio; 0 - Oxigênio; C - Carbono; F - Flúor; Si - Silício; Ca - Cálcio; Al - Alumínio.

\section{DISCUSSÃO}

Este estudo mostrou que o efeito de CLX em cultura monoespécie de E. coli sobre superfície de Ti com microtopografia foi determinado pela concentração de CLX. A análise dos dados de contagem de UFC sugere uma redução no número de colônias com o aumento da concentração de CLX. Os resultados indicaram a eficácia da CLX como agente antimicrobiano e corroboram com o efeito dose-resposta de CLX para reduzir o biofilme formado em Ti evidenciados na literatura ${ }^{12}$.

A CLX é uma substância química classificada como um antisséptico de largo espectro contra bactérias Gram-positivas e Gram-negativas. 0 modo de ação antibacteriano se dá através da alteração da membrana celular bacteriana, o que resulta em um extravasamento do conteúdo interno acarretando em morte celular ${ }^{18}$. Estágios iniciais da peri-implantite podem ser tratados através do controle de biofilme peri-implantar por meio de instrução de higiene oral, desinfecção da superfície do implante e bochechos com antimicrobianos. Já o tratamento de estágios avançados de peri-implantite - caracterizados por aumento da profundidade de sondagem, presença de exsudato e perda óssea -, na maioria dos casos, requer técnicas cirúrgicas ressectivas ou regenerativas ${ }^{19}$.

A menor concentração de CLX de $0,12 \%$ utilizada no presente estudo mostrou um efeito na redução do biofilme formado nas superfícies de Ti. Essa mesma concentração, 0,12\%, também causa redução efetiva em biofilmes de Streptococcus mutans formados in vitro em superfícies dentárias ${ }^{20}$. 0 diversificado ecossistema bacteriano presente na boca pode ser mimetizado por modelos de biofilme, no entanto esses modelos não foram usados. Neste estudo, foi definido que o desafio bacteriano utilizado para avaliar as terapias de descontaminação das superfícies de titânio por agentes químicos seria desenvolvido sob a forma de monoespécie, E. coli. As bactérias foram cultivadas sobre as amostras de titânio por um período de 24 horas, tempo similar ao utilizado por trabalhos com propostas semelhantes ${ }^{21}$. E. coli é um microrganismo, pertencente à família Enterobacteriaceae, presente no trato gastrintestinal dos animais e do homem, fazendo parte da microbiota da cavidade bucal e intestinal. São bastonetes Gram-negativos, não esporulados e anaeróbios facultativos, e crescem bem em meio de cultura sintético, que contém nutrientes simples e fermentam açúcares ${ }^{14}$. De forma geral, resultados de estudos in vitro com biofilmes monoespécie são encontrados na literatura e podem ser utilizados para interpretação de interações mais complexas de biofilmes in vivo ${ }^{22}$.

Os resultados obtidos pela MEV não mostraram diferenças em relação à morfologia das superfícies após a descontaminação. Esse resultado era esperado devido à natureza dos tratamentos propostos, nos quais não existe uma ação mecânica mais efetiva que possa causar danos à superfície. 
Analisando os dados da EDS para os teores percentuais de Ti nas amostras tratadas com CLX, observa-se uma redução significativa do nível percentual de Ti na superfície e, ao mesmo passo, existe um aumento dos níveis percentuais de 0 . Comparando este fato com a análise microbiológica proposta em trabalhos prévios ${ }^{23}$, nos quais CLX gel $2 \%$ apresenta ausência de unidades formadoras de colônia, esta superfície com alto grau de 0 pode ter configurado uma resposta química, que facilitou a descontaminação da superfície. Devido à característica da técnica de EDS, que é apenas de análise de elementos químicos, não é possível afirmar que foi gerada uma fase cristalina de óxido de titânio $\left(\mathrm{TiO}_{2}\right)$ após a aplicação do agente descontaminante. Estudos mostram que a ocorrência da formação de $\mathrm{TiO}_{2}$ é importante, podendo inclusive influenciar na desestabilização molecular bacteriana ${ }^{12,16}$.

Clinicamente, para realizar a descontaminação das superfícies dos implantes durante o tratamento da peri-implantite, são sugeridos o uso de diferentes métodos mecânicos e químicos, e/ou sua associação. Os principais métodos abordados na maioria dos estudos são: raspagem da superfície com curetas de plástico, uso de jato de ar abrasivo, uso do ácido cítrico, uso de pasta à base de tetraciclina, uso de gel de metronidazol e de solução salina fisiológica, como também se observa a indicação do uso da CLX ${ }^{24}$. Apesar de vários estudos abordarem diversas técnicas e opções de tratamento para essa complicação, ainda não existe um único tratamento que possa ser considerado o padrão ouro ${ }^{7}$. Tal dificuldade em se estabelecer a opção de tratamento ideal pode estar relacionada à característica da própria doença, com uma etiologia complexa e multifatorial ${ }^{10}$. 0 objetivo do uso de agentes químicos é a total descontaminação da superfície de $\mathrm{Ti}$, no entanto essa situação de completa descontaminação não é observada na literatura ${ }^{8}$. Uma diminuição significante da concentração superficial de Ti, assim como um aumento de 0 , observados neste estudo, podem influenciar possíveis resultados clínicos, considerando que o potencial de osseointegração e re-osseointegração são influenciados pela rugosidade e pela composição química da superfície ${ }^{25}$.

Os grupos submetidos a concentrações maiores de CLX e a um tempo de exposição maior tiveram melhores resultados, sendo esse resultado de significativa importância para justificar estudos futuros em demais superfícies de titânio com outros métodos e formas de descontaminação. Os resultados obtidos sugerem que a CLX é eficaz e pode ser considerada como opção de método químico de descontaminação de superfícies de Ti.

\section{CONCLUSÃO}

Apesar dos limites metodológicos deste estudo, pode-se concluir que o uso de CLX gel a $2 \%$ causou a descontaminação mais efetiva em superfícies de Ti com microtopografia colonizadas por E. coli e que sua aplicação resultou na diminuição do percentual de Ti e no aumento do teor de 0 .

\section{AGRADECIMENTOS}

Gostaríamos de agradecer à Empresa NEODENT ${ }^{\circledR}$ (Curitiba, Paraná, Brasil), pelo fornecimento dos discos de Ti usados neste estudo. Ao Centro de Microscopia Eletrônica (CME) da Universidade Federal do Paraná (UFPR) e ao Dr. Thiago Gomes da Silva, pelo suporte com a MEV e EDS. À Fundação Araucária, Paraná, Brasil, pela concessão de Bolsa do Programa PIBIC a Viviane Maria Rankel, e à Coordenação de Aperfeiçoamento de Pessoal de Nível Superior (CAPES), pela concessão de Bolsa de Mestrado a Marcelo Yudi Sakamoto. 


\section{REFERÊNCIAS}

1. Derks J, Hakansson J, Wennstrom JL, Tomasi C, Larsson M, Berglundh T. Effectiveness of implant therapy analyzed in a Swedish population: early and late implant loss. J Dent Res. 2015 Mar;94(3 Suppl):44S-51S. http://dx.doi.org/10.1177/0022034514563077. PMid:25503901.

2. Mokashi R, Sudan PS, Dharamsi AM, Mohanty R, Misurya AL, Kaushal P. Risk assessment in long-term survival rates of dental implants: a prospective clinical study. J Contemp Dent Pract. 2018 May;19(5):587-90. http://dx.doi.org/10.5005/jp-journals-10024-2303. PMid:29807971.

3. Schwarz F, Derks J, Monje A, Wang HL. Peri-implantitis. J Periodontol. 2018 Jun;89(Suppl 1):S267-90. http://dx.doi.org/10.1002/JPER.16-0350. PMid:29926957.

4. Caton JG, Armitage G, Berglundh T, Chapple ILC, Jepsen S, Kornman KS, et al. A new classification scheme for periodontal and peri-implant diseases and conditions - introduction and key changes from the 1999 classification. J Clin Periodontol. 2018 Jun;45(Suppl 20):S1-8. http://dx.doi.org/10.1111/jcpe.12935. PMid:29926489.

5. Faveri M, Figueiredo LC, Shibli JA, Perez-Chaparro PJ, Feres M. Microbiological diversity of periimplantitis biofilms. Adv Exp Med Biol. 2015;830:85-96. http://dx.doi.org/10.1007/978-3-319-110387_5. PMid:25366222.

6. Ryu H-S, Kim Y-I, Lim B-S, Lim Y-J, Ahn S-J. Chlorhexidine uptake and release from modified titanium surfaces and its antimicrobial activity. J Periodontol. 2015 Nov;86(11):1268-75. http://dx.doi.org/10.1902/jop.2015.150075. PMid:26156675.

7. Schwarz F, Sahm N, Mihatovic I, Golubovic V, Becker J. Surgical therapy of advanced ligature-induced peri-implantitis defects: cone-beam computed tomographic and histological analysis. J Clin Periodontol. 2011 Oct;38(10):939-49. http://dx.doi.org/10.1111/j.1600-051X.2011.01739.x. PMid:21883358.

8. Sousa V, Mardas N, Spratt D, Boniface D, Dard M, Donos N. Experimental models for contamination of titanium surfaces and disinfection protocols. Clin Oral Implants Res. 2016 Oct;27(10):1233-42. http://dx.doi.org/10.1111/clr.12735. PMid:26864128.

9. James P, Worthington HV, Parnell C, Harding M, Lamont T, Cheung A, et al. Chlorhexidine mouthrinse as an adjunctive treatment for gingival health. Cochrane Database Syst Rev. 2017 Mar;3(3):CD008676. http://dx.doi.org/10.1002/14651858.CD008676.pub2. PMid:28362061.

10. Figuero E, Graziani F, Sanz I, Herrera D, Sanz M. Management of peri-implant mucositis and periimplantitis. Periodontol 2000. 2014 Oct;66(1):255-73. http://dx.doi.org/10.1111/prd.12049. PMid:25123773.

11. Kotsakis GA, Lan C, Barbosa J, Lill K, Chen R, Rudney J, et al. Antimicrobial agents used in the treatment of peri-implantitis alter the physicochemistry and cytocompatibility of titanium surfaces. J Periodontol. 2016 Jul;87(7):809-19. http://dx.doi.org/10.1902/jop.2016.150684. PMid:26923474.

12. Souza JGS, Lima CV, Costa Oliveira BE, Ricomini-Filho AP, Faveri M, Sukotjo C, et al. Dose-response effect of chlorhexidine on a multispecies oral biofilm formed on pure titanium and on a titaniumzirconium alloy. Biofouling. 2018 Nov;34(10):1175-84. http://dx.doi.org/10.1080/08927014.2018.1557151. PMid:30744421.

13. Schwartz-Filho HO, Morandini ACF, Ramos-Junior ES, Jimbo R, Santos CF, Marcantonio E Jr, et al. Titanium surfaces with nanotopography modulate cytokine production in cultured human gingival fibroblasts. J Biomed Mater Res A. 2012 0ct;100(10):2629-36. http://dx.doi.org/10.1002/jbm.a.34200. PMid:22615216.

14. Nataro JP, Kaper JB. Diarrheagenic Escherichia coli. Clin Microbiol Rev. 1998 Jan;11(1):142-201. http://dx.doi.org/10.1128/CMR.11.1.142. PMid:9457432. 
15. Kuo H-N, Mei H-I, Liu T-K, Liu T-Y, Lo L-J, Lin C-L. In Vitro laser treatment platform construction with dental implant thread surface on bacterial adhesion for peri-implantitis. BioMed Res Int. 2017;2017:4732302. http://dx.doi.org/10.1155/2017/4732302. PMid:28791302.

16. Kotsakis GA, Black R, Kum J, Berbel L, Sadr A, Karoussis I, et al. Effect of implant cleaning on titanium particle dissolution and cytocompatibility. J Periodontol. 2020 Aug 26. https://doi.org/10.1002/JPER.20-0186. Epub ahead of print. PMid: 32846000.

17. Wheelis SE, Gindri IM, Valderrama P, Wilson TG Jr, Huang J, Rodrigues DC. Effects of decontamination solutions on the surface of titanium: investigation of surface morphology, composition, and roughness. Clin Oral Implants Res. 2016 Mar;27(3):329-40. http://dx.doi.org/10.1111/clr.12545. PMid:25580643.

18. Quirynen M, Teughels W, De Soete M, van Steenberghe D. Topical antiseptics and antibiotics in the initial therapy of chronic adult periodontitis: microbiological aspects. Periodontol 2000. 2002;28(1):72-90. http://dx.doi.org/10.1034/j.1600-0757.2002.280104.x. PMid:12013349.

19. Ramanauskaite A, Juodzbalys G, Tözüm TF. Apical/retrograde periimplantitis/implant periapical lesion: etiology, risk factors, and treatment options: a systematic review. Implant Dent. 2016 Oct;25(5):684-97. http://dx.doi.org/10.1097/ID.0000000000000424. PMid:27579555.

20. Ccahuana-Vásquez RA, Cury JAS. mutans biofilm model to evaluate antimicrobial substances and enamel demineralization. Braz Oral Res. 2010 Apr-Jun;24(2):135-41. http://dx.doi.org/10.1590/S1806-83242010000200002. PMid:20658029.

21. Henderson E, Schneider S, Petersen FC, Haugen HJ, Wohlfahrt JC, Ekstrand K, et al. Chemical debridement of contaminated titanium surfaces: an in vitro study. Acta Odontol Scand. 2013 MayJul;71(3-4):957-64.. http://dx.doi.org/10.3109/00016357.2012.734423. PMid:23140518.

22. Karring ES, Stavropoulos A, Ellegaard B, Karring T. Treatment of peri-implantitis by the Vector system. Clin Oral Implants Res. 2005 Jun;16(3):288-93. http://dx.doi.org/10.1111/j.1600-0501.2005.01141.x. PMid:15877748.

23. Matos AO, de Almeida AB, Beline T, Tonon CC, Casarin RCV, Windsor LJ, et al. Synthesis of multifunctional chlorhexidine-doped thin films for titanium-based implant materials. Mater Sci Eng C Mater Biol Appl. 2020 Dec;117:111289. http://dx.doi.org/10.1016/j.msec.2020.111289. PMid:32919650.

24. Stellini E, Migliorato A, Mazzoleni S, Mottola A, Lombardi L, Favero GA. Topical treatment of periimplantitis with metronidazole dental gel 25\%. Clinical analysis and microbiological control. Minerva Stomatol. 2000 Jan-Feb;49(1-2):59-67. PMid:10932909.

25. Subramani K, Wismeijer D. Decontamination of titanium implant surface and re-osseointegration to treat peri-implantitis: a literature review. Int J Oral Maxillofac Implants. 2012 Sep-Oct;27(5):1043-54. PMid:23057016.

\section{CONFLITOS DE INTERESSE}

Os autores declaram não haver conflitos de interesse.

\section{*AUTOR PARA CORRESPONDÊNCIA}

Humberto Osvaldo Schwartz-Filho, UFPR - Universidade Federal do Paraná, Departamento de Estomatologia, Rua Prefeito Lothário Meissner 632, Jardim Botânico, 80210-170 Curitiba, PR, Brasil, e-mail: betoschwartz@ufpr.br 